\title{
Clinical Psychology in Penitentiary Practice and Training of Psychologists
}

\author{
Renata Kiseleva ${ }^{1}{ }^{*}$ Vladimir Orlov ${ }^{1}$ \\ ${ }^{1}$ Academy of the Federal Penitentiary Service of Russia, Russia \\ *Email: renatakis@yandex.ru
}

\begin{abstract}
The article presents research data on the severity of mental abnormalities and their variants found among the convicts serving sentences in penitentiary institutions of Russia. The data on the prevalence of mental disorders among convicts are presented. Criminal behavior can be a consequence of the presence of certain anomalies in a person, and vice versa, the occurrence of anomalies can be a consequence of leading a criminal lifestyle, being in a criminal environment or long-term imprisonment. These factors determine the development of pathological changes in the psyche of convicts, but do not exclude their sanity. According to the latest research results, from $70 \%$ to $80 \%$ of convicts serving sentences in correctional institutions of the federal penitentiary service of Russia have some kind of mental abnormalities. The features of psychological correction consist in taking into account the symptoms and consequences of mental disorders of convicts in the development of individual programs of adaptation and resocialization of this category of convicts. The purpose of the study was to substantiate the need for additional education in the field of clinical psychology by prison psychologists.
\end{abstract}

Keywords: Convicts, Mental abnormalities, Clinical psychology, Training.

\section{INTRODUCTION}

In correctional institutions of the federal penitentiary service of Russia, convicts are held for various crimes. Traditionally, a large group consists of the convicts who have committed violent crimes. The people who commit crimes against the life and health of other people have special personality traits that determine their life path [1]. Very often, the commission of crimes is combined with increased aggressiveness of criminals, extreme cruelty, emotional callousness. F.S. Safuanov states that personal factors predominate among other determinants of aggression [5]. According to Yu.M. Antonyan, criminal behavior can be a consequence of the presence of certain anomalies in a person, and vice versa, the occurrence of anomalies can be a consequence of leading a criminal lifestyle, being in a criminal environment or prolonged imprisonment. These factors determine the development of pathological changes in the psyche of convicts, but do not exclude their sanity [3]. Mental properties and processes in these individuals undergo significant changes, they are reflected in personal disorders, but do not lead to limitations of legal capacity and ability to work.

\section{RESEARCH METHODOLOGY}

Mental disorders that do not exclude a person's sanity are called "mental abnormalities". In psychiatry, an anomaly is any deviation from the norm, although there is no unambiguous definition of the norm. Norm refers to the most typical behavior characteristic of the majority of the human population. Thus, under mental anomalies fall all deviations of the psyche that arise under the influence of endogenous and exogenous factors. The environment of convicts is very rich in examples of various anomalies [2]. We have carried out a methodological analysis of various mental disorders that occur among convicts. It is based on the works of domestic and foreign authors on this issue, as well as their own experience in the penitentiary system. The methods of observation, survey, biographical analysis, and study of products of activity were used in the research. 


\section{RESEARCH RESULT}

According to the latest results of statistical studies, from $70 \%$ to $80 \%$ of the convicts serving sentences in institutions of the Federal Penitentiary Service of Russia have certain mental disorders that do not exclude their sanity [9]. Persons with mental disabilities differ in many personal characteristics from healthy people. Among the convicts serving sentences in correctional institutions of the Federal Penitentiary Service of Russia, for premeditated murder have mental abnormalities (22.3\%), rape, assault, robbery (48.7\%). These persons have a criminal past, i.e. they were previously sentenced to serve a sentence without deprivation of liberty $(34.3 \%)$, or with a suspended sentence $(45.6 \%)$, or were registered with the police in juvenile affairs units $(76.5 \%)$.

Among the various anomalies of the psyche, various psychopathic disorders of mood and behavior, as well as some extremely pronounced character traits that acquire the form of accentuations, attract attention. Accentuations of character, although they are an extreme version of the norm, make the person of the convicted person vulnerable to negative internal and external influences. They cause violent specific reactions in extreme situations [8]. Unlike psychopathy accentuation of character do not cause total social disadaptation of the person. However, they determine the most acute manifestation of negative traits at the time of committing a crime and while serving a sentence. Among the types of accentuations, the excitable and stuck types are particularly distinguished in criminal terms. Among juvenile convicts, the character accentuations are noticeable in $90 \%$ of cases.

Among those convicted of various types of crimes, there are many people who have various borderline disorders that do not limit their legal capacity. This is clearly evident in the case of persons who have been repeatedly convicted of similar crimes. Among borderline disorders, the most common are depression, traumatic disorders, distress, anxiety and hysterical disorders, somatoform reactions, sexual dysfunctions and disorders of sexual identification [1].

The vast majority of convicts serving sentences related to deprivation of liberty suffer from alcoholism and drug addiction. The use of psychoactive substances causes irreparable damage to the human psyche, leading to personal degradation. Under their influence, there is a disinhibition of behavior, a decrease in the criticality of actions (both their own and the actions of other people), falsehood and selfishness develop. Aggression, the surge of which is provoked by psychoactive substances, finds a way out in causing harm to others and ultimately leads to the commission of crimes [7]. The loss of moral guidelines, combined with encephalopathy caused by the death of brain cells, leads to the disintegration of the individual. Such people live by momentary satisfaction of needs, do not realize life prospects, do not make further plans and do not want to change completely.

Most people convicted of premeditated murder are sociopaths. Under sociopathy, it is customary to understand human behavior that goes against generally accepted norms, including moral ones. The concept of sociopathy, according to $\mathrm{K}$. Kiehl, includes a narrower concept of psychopathy [10]. Psychopathy has a genetic origin and is associated with damage to brain structures. Psychopaths are characterized by a complete disregard for the laws, they are self-centered, arrogant, inventive in terms of achieving their own goals, impulsive and extremely cruel. Psychopaths are not able to establish and maintain close relationships. These people do not know what empathy is and do not have compassion for the victims. Lack of conscience and remorse for the crimes committed are the most characteristic features of them. The study of their personal characteristics was carried out by R. Hare, who compiled a list of psychopathic traits [12].

The neurophysiological basis of sociopathy is an organic lesion of the brain in the temporal and frontal cortex, which are responsible for the processes of excitation and inhibition, or the structures of the limbic system, which are responsible for the formation of emotions. Sociopaths are really not able to experience the same emotions that other people, they cannot sympathize and it is impossible to correct this [12]. Along with high intelligence, sociopaths have a tendency to manipulate, which makes the process of their psychocorrection extremely difficult. For example, in the process of psychological counseling, the convicted person repents of the crime committed and expresses a desire to change, asks for the help of a psychologist. We begin to plan ways of psychocorrective work with him, but accidentally learn that this convict boasts to others that he was able to deceive the psychologist and that he "is on the hook" [5].

The consequences of traumatic brain injuries, organic lesions of the central nervous system take the form of rapid fatigue, exhaustion, increased anxiety and irritability, frequent mood swings. In the state of health of the convicts, dizziness, headaches, loss of orientation in space, tremor of the limbs, inability to concentrate are noted. With deep lesions, hysteroid reactions are observed.

According to sample data, persons with residual phenomena of traumatic brain injuries among all studied offenders, including healthy ones, make up about $6 \%$, and without taking into account the latter - about $10 \%$. The proportion of criminals suffering from organic diseases of the central nervous system, respectively, is from $3 \%$ to $6 \%$. Mental disorders that occur in a separate period of organic brain diseases have a clinical 
picture similar to the above-described consequences of traumatic brain injuries. The most common are asthenic and psychopathic disorders that have a significant impact on behavior [9].

Mental retardation of varying degrees accompanies spontaneous reactions of criminals, demonstrates a significant decrease in intelligence and an inability to assess the consequences of their actions. The most common diagnosis is oligophrenia in the degree of mild debility [1]. According to the author's own research conducted in the Ryazan educational colony in 2012, the number of juvenile convicts who show signs of mental retardation, such as simplified speech, stereotyped behavior, violation of associativity and logical thinking, uncriticism to themselves, inability to foresee the consequences of their actions, etc., reaches $25-30 \%$ of the total number of convicts [4].

Schizophrenia, paranoid disorder and epilepsy are the most common mental illnesses that are diagnosed in convicts. Schizophrenia is a disease in which pathological changes in mental processes increase, their de-coordination occurs. Such people may not understand the consequences of their actions, are uncritical about themselves. Practice shows that criminals suffering from schizophrenia are rarely recognized as sane and serve their sentences in specialized medical institutions, but the progressive growth of this disease among the population steadily leads to an increase in the number of convicts with a mild degree of severity of the disease recognized as sane. Schizophrenia in convicts can also occur atypically. Sluggish schizophrenia manifests itself in the simulated behavior of convicts [3].

Paranoid disorder involves the formation of valuable ideas, delusions of damage. Under their influence, a person develops a special suspicion, jealousy, resentment, stubbornness. It is extremely difficult for such convicts to maintain social contacts, they do not know how to forgive insults. All of them are serving sentences for committing serious violent crimes. While serving their sentence, they become uncritical of their behavior, distort real facts, and are extremely conflicted [13].

Another psychiatric disease that occurs among convicts is epilepsy. It is accompanied by uncontrolled convulsive seizures or attacks, loss of sensitivity and consciousness. It is based on birth injuries, intoxication, severe nervous shocks. The peculiarity of the disease leaves an imprint on the character of a person, making him suspicious, touchy and very cruel. Slowness of reactions, violations in adaptation, difficulties in mastering new things lead to the commission of illegal actions [9].

The presence of mental abnormalities of convicts reduces their adaptive abilities, hinders successful rehabilitation work, and creates problems in relations with the administration of correctional institutions [6]. Stubbornness, irritability, a tendency to conflict and the use of forceful methods of solving problems lead to frequent violations of the regime of serving a sentence. The analysis of disciplinary practice shows that persons with certain mental disorders most often receive penalties. It is important to remember that during the period of exacerbation of diseases, convicts with mental disabilities may not obey the requirements of the regime not by intent, but due to pathological internal processes, which make them immune to educational and disciplinary measures [6].

Foreign approaches to providing psychotherapeutic assistance to convicts with mental abnormalities are based on the use of medication [11]. Often convicted persons need to prescribe compulsory measures of a medical nature, combined with the execution of the sentence. The staff of penitentiary institutions of developed foreign countries must have a psychiatrist. Outpatient compulsory observation and treatment by a psychiatrist, including the use of neuroleptics to reduce mental disorders, will significantly improve their mental state, will contribute to the achievement of the goals of punishment. In addition to drug therapy, all the examined patients were shown psychotherapeutic influence, which should be provided by the psychologist of the correctional institution [6]. A similar but milder concept of assistance to convicts is being implemented in the domestic penitentiary system. In Russia, psychiatric care for convicts in correctional institutions is provided by part-timers, and all psychotherapeutic work with convicts with mental abnormalities is carried out on a voluntary basis. The most effective methods of psychocrrectionary influence are currently recognized as art therapy, bibliotherapy, and occupational therapy. These methods make it possible to relieve tension, overcome conflict, and form new behavioral stereotypes [5]. Rehabilitation measures combine medical, psychological and social aspects [4].

An example of such work is the experience of the psychological service of the Federal Penitentiary Service of Russia in the Voronezh Region. Its employees have prepared a number of practical instructions and methodological recommendations, according to which psychological laboratories provide support for convicts with signs of mental disorders [6]. However, not all prison psychologists are able to carry out psychotherapeutic work with convicts who have mental abnormalities. This requires special competencies in the field of psychotherapy and clinical psychology. Studying in the specialty "Psychology of official activity", psychologists of departmental universities of the Federal Penitentiary Service of Russia study clinical psychology in a limited volume. These hours are not enough for the formation of 
professional competencies necessary for working with convicts with mental abnormalities [4].

\section{CONCLUSIONS}

Thus, the prevalence of mental abnormalities among convicts, both in Russia and in foreign countries, ranges from $60 \%$ to $80 \%$. In isolation, psychopathic traits are hypertrophied, acquire the most unfavorable course, go into the stage of decompensation, provoke the manifestation of aggressive and autoaggressive tendencies, and contribute to the growth of psychopathological syndromes. Psychoprophylactic measures should focus on reducing psychoemotional stress, overcoming anxiety, and actively engaging in socially useful activities.

Taking into account the growing number of mental anomalies among convicts, there is a need to determine not only methodically adequate means of psychocorrection, but also to develop a general preventive paradigm of impact in penitentiary institutions. Psychological and correctional work with convicts should take into account their individual psychological characteristics, the presence of deviations and diseases, typological features of the course. Among psychotherapeutic approaches, in our opinion, behavioral and emotional-figurative therapy should prevail, since these approaches correspond to the personal characteristics of convicts with mental abnormalities as much as possible.

Not having sufficient knowledge in the field of clinical psychology, prison psychologists do not fully understand what is happening to a particular convict, they build work with him intuitively. As our experience in the system of advanced training and professional retraining shows, practical prison psychologists are not always ready for such practical activities, they have special difficulties in carrying out diagnostic and psychocorrective measures with convicts who have certain mental abnormalities.

The subject of clinical psychology is the study of the manifestations of various mental disorders, disorders of personality development, factors contributing to the occurrence of deviations and the possibilities of their psychocorrection. This discipline is located at the intersection of medicine and psychology and is divided into three separate sections: neuropsychology, psychosomatics, and pathopsychology.

The situation with the mental health of convicts serving sentences in correctional institutions of the Federal Penitentiary Service of Russia dictates special requirements for the education of prison psychologists, their knowledge and work skills. There is a need for additional education in the programs "Clinical Psychology" and the application of additional knowledge in pathopsychology and neuropsychology in the practice of a prison psychologist.

\section{REFERENCES}

[1] Psychological characteristics of convicts with personality disorders/ed. D.V. Sochivko, Ryazan, Academy of the Federal Penitentiary Service of Russia, 2017, 133 p. (In Russ.).

[2] N.D. Uzlov, Personality, disease, criminality: selected articles on clinical and penitentiary psychology, Penza: SIC "Sociosphere", 2014, 220 p.

[3] V.G. Pechersky, N.V. Maksimenko, D.E. Ivanov, Research of personal characteristics of convicted persons for violent and mercenary crimes, Experimental psychology in Russia: traditions and prospects, Moscow: IPRAN, 2010, pp. 714-719 (In Russ.).

[4] R.N. Kiseleva, The need for clinical education of penitentiary psychologist, Collection of the VII International Conference "Penitentiary system and society: experience of interaction", Perm, 2020, pp. 171-172 (In Russ.).

[5] R.N. Kiseleva, T.P. Skripkina, The emotionallyshaped therapy in psycho-correction work with the convicted persons, Journal of applied legal psychology 1(50) (2020) 73-79.

[6] Krasnenkova S.A. Psychological and pedagogical support of suspects, accused and convicted persons with mental disorders [Electronic resource], Novainfo Iss. 31-1, 2015. Retrieved from: https://novainfo.ru/article/3078 $\quad$ (accessed: 10.01.2020) (In Russ.)

[7] F.S. Safuanov, M.G. Sorokova, A.K. Sokovets, Pro- and anti-aggressive personal factors in accused persons with mental disorders in crimes against the person [Electronic resource], Psychology and law Vol. 9 Iss. 3 (2019) 158-177. Retrieved from: https://psyjournals.ru/psyandlaw/2019/n3/index.sht ml (accessed: 20.01.2020) (In Russ.).

[8] F.S. Safuanov, A.S. Kalashnikova, A.E. Tsarkov, Clinical and psychological factors of criminal aggression [Electronic resource], Psychology and Law Vol. 7 Iss. 4 (2017) 44-58. Retrieved from: https://psyjournals.ru/psyandlaw/2019/n3/109389.s html (accessed: 20.01.2020) (In Russ.).

[9] B.A. Spasennikov, Clinical and criminological analysis of personality disorders in convicts [Electronic resource], All-Russian Criminological Journal 2 (2014) 33-40. Retrieved from: 
https://cyberleninka.ru/article/n/kliniko-

kriminologicheskiy-analiz-rasstroystv-lichnosti-uosuzhdennyh (accessed: 12.01.2020) (In Russ.).

[10] A. Kent, Kiehl The psychopath whisperer The Science of Those Without Conscience Copyright, 2014, p. 165.

[11] S.O. Lilienfeld, Conceptual problems in the assessment of psychopathy, Clinical Psychology Review 14 (2007) 17-38.

[12] Hare R.D. Psychological instruments in the assessment of psychopathy, International Handbook on Psychopathic Disorders and the Law. N.Y., 2007. pp. 41-67.

[13] R. Blackburn, The psychology of criminal conduct [Electronic resource]. Retrieved from: //https://www.researchgate.net/publication/290287 $\underline{095}$ 